\title{
Experimental determination of volatile organic compounds emitted by Thymus vulgaris
}

\author{
K. Chetehouna ${ }^{1}$, L. Courty ${ }^{1,2}$, L. Lemée ${ }^{3}$, J. P. Garo ${ }^{2}$ \& P. Gillard ${ }^{1}$ \\ ${ }^{1}$ Laboratoire PRISME, Bourges, France \\ ${ }^{2}$ Institut P', ENSMA, Université de Poitiers, \\ Futuroscope Chasseneuil, France \\ ${ }^{3}$ Université de Poitiers, Poitiers, France
}

\begin{abstract}
Thymus vulgaris is a common Mediterranean vegetal species often involved in forest fires. The aim of this work is to characterize the VOCs emitted by the needles of this plant as functions of temperature. Experiments are performed using a flash pyrolysis apparatus. The influence of two parameters, namely the heating time and heating rate are studied: the highest VOCs' emissions are found for a heating time of $30 \mathrm{~s}$ at $5000 \mathrm{~K} / \mathrm{s}$. Two major compounds are identified for all the temperatures, thymol and $p$-cymene. The total amount of VOCs emitted increases with temperature and except for the three lowest temperatures, thymol represents more than $50 \%$ of the gas mixture. Results are compared to literature available data and to the emissions behaviour of other vegetal species.

Keywords: Thymus vulgaris, VOCs emission, flash pyrolysis, forest fires.
\end{abstract}

\section{Introduction}

Vegetation is the engine of combustion in forest fires and its characterization is important to accurately modelling fires propagation. Before the pyrolysis temperature, many Volatile Organic Compounds (VOCs) are emitted by most of the vegetal species. These VOCs are mostly monoterpenes $\left(\mathrm{C}_{10} \mathrm{H}_{16}\right)$ and sesquiterpenes $\left(\mathrm{C}_{15} \mathrm{H}_{24}\right)$ and they have very low values of lower flammability limits, namely less than $1 \%$ vol. in air [1]. For this reason, they are much more flammable than typical pyrolysis products $\left(\mathrm{CO}, \mathrm{CH}_{4}\right.$, etc. $)$ and they should be taken into account for the characterization of vegetation. We can find several 
works in the literature dealing with the VOCs' emissions of various vegetal species at ambient temperature. Indeed, Owen et al. [2] studied the emissions of forty Mediterranean plant species and observed thirty two compounds. Ormeño et al. [3] investigated the emissions of three typical Mediterranean plants for atmospheric conditions. The VOCs' emissions of Pinus pinea needles, branches and female cones were analyzed by Macchioni et al. [4] at ambient temperature and they have shown that limonene is the major constituent emitted by these three plant parts. There is a lack in the literature on the VOCs' emissions of plants as functions of temperature, which is essential for forest fire models because large amounts of VOCs are emitted for temperatures higher than the ambient temperature. We can note the studies of Chetehouna et al. [5] and Barboni et al. [6] for respectively the emissions of Rosmarinus officinalis in a hermetic enclosure and the emissions of Pinus laricio, Pinus pinaster and Cistus monspeliensis using an Automatic Thermal Desorber (ATD). In a previous work [7], we characterized the emissions of Rosmarinus officinalis in a flash pyrolysis apparatus and identified $\alpha$-pinene as the main component between 343 and 453 $\mathrm{K}$ and the maximum emission temperature has been found around $440 \mathrm{~K}$.

Thymus vulgaris is a well known aromatic plant, which is a typical species of the Mediterranean basin involved in forest fires [8]. Its emissions as function of temperature have never been studied. The characterization of the VOCs emitted by this species will therefore be useful to better understand forest fires behavior.

The main purpose of this paper is to characterize the VOCs' emissions of heated needles of Thymus vulgaris in order to extend the existing literature database on plants VOCs' emissions at different temperatures. The second section is devoted to the presentation and to the description of the VOCs' emissions experimental setup. The emissions of Thymus vulgaris needles as function of preheat temperature are presented and discussed in the third section.

\section{Experimental setup and procedures}

This section deals with the characterization of the VOCs emitted by needles of a typical Mediterranean region species, namely Thymus vulgaris. The needles emission measurements are performed using a flash pyrolysis apparatus (CDS Pyroprobe 5150). This device is widely used to characterize the thermal degradation of various materials [9-11]. Needle samples with an average mass of $2.3 \mathrm{mg}$ are placed inside a $40 \mathrm{~mm} \times 2 \mathrm{~mm}$ i.d. quartz tube and heated up to the desired temperature during a variable lapse of time. The temperature rise can also be varied up to a maximum heating rate of $5000 \mathrm{~K} . \mathrm{s}^{-1}$. The flash pyrolysis device consists of an inductively heated coil to heat the samples from room temperature to the selected temperature. Helium is used as carrier gas to transport the emitted VOCs to the gas chromatograph coupled with mass spectrometer (GC/MS) apparatus via a heated $(553 \mathrm{~K})$ transfer line. GC/MS analyses are realized with a Trace Ultra GC-Thermo DSQ II equipped with a DB5 capillary column ( $30 \mathrm{~m}$ long, $0.25 \mathrm{~mm}$ i.d., film thickness $0.25 \mu \mathrm{m})$. The column temperature was programmed from 333 to $473 \mathrm{~K}$ at a rate of $5 \mathrm{~K} \cdot \mathrm{min}^{-1}$ 


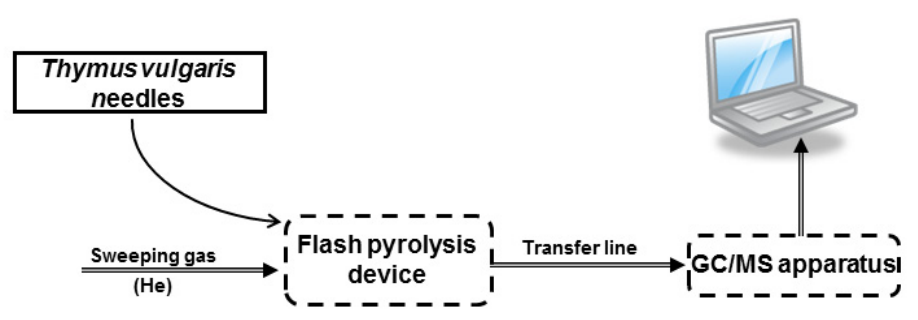

Figure 1: Schematic overview of the emission experimental setup.

and held for 5 minutes at $473 \mathrm{~K}$. Mass spectra are recorded in the electron impact mode with ionization energy of $70 \mathrm{eV}$. Figure 1 shows a schematic overview of the described experimental facilities.

Identification of VOCs is based on a comparison of their mass spectra with the NIST mass spectral library, with data from literature and with mass spectra and retention times of reference compounds ( $\alpha$-pinene, limonene). These reference compounds can also be used to make calibration curves for quantification. The range of temperature selected is between 343 and $453 \mathrm{~K}$ in order to determine VOCs' emissions before their pyrolysis phase. Three experiments are performed for each temperature in order to ensure the repeatability.

\section{Results and discussions}

As indicated in the introduction, we studied in a previous work the emissions of Rosmarinus officinalis needles between 343 and $453 \mathrm{~K}$ and large amounts of VOCs were emitted for temperatures higher than $400 \mathrm{~K}$ [7]. In this study, we have selected the temperature $453 \mathrm{~K}$ to study the effects of two parameters: the heating time and heating rate. They are varied respectively from 20 to $60 \mathrm{~s}$ for a heating rate of $5000 \mathrm{~K} / \mathrm{s}$ and from 1 to $5000 \mathrm{~K} / \mathrm{s}$ for a heating time of $30 \mathrm{~s}$. A mixture of 13 compounds is identified and these VOCs are the same for different values of heating time and heating rate. They are presented in Table 1 along with their retention times and molecular formulas.

We can see in this table that six families of molecules are identified: monoterpenes $\left(\mathrm{C}_{10} \mathrm{H}_{16}, \mathrm{C}_{10} \mathrm{H}_{14}\right)$, sesquiterpenes $\left(\mathrm{C}_{15} \mathrm{H}_{24}\right)$, and oxygenated compounds: monoterpenic alcohols, monoterpenic phenols, monoterpenic ether $\left(\mathrm{C}_{10} \mathrm{H}_{14} \mathrm{O}, \mathrm{C}_{10} \mathrm{H}_{16} \mathrm{O}\right.$ and $\left.\mathrm{C}_{10} \mathrm{H}_{18} \mathrm{O}\right)$. It can be noticed that this species present a wider range of chemical families than Rosmarinus officinalis, which emits only five different families [7].

Figures 2 and 3 illustrate the influence of the heating time and heating rate on the emissions of VOCs by Thymus vulgaris species. It is clear in Figure 2 that the three major compounds, namely thymol $\left(\mathrm{C}_{10} \mathrm{H}_{14} \mathrm{O}\right)$, $p$-cymene $\left(\mathrm{C}_{10} \mathrm{H}_{14}\right)$ and $\gamma$ terpinene $\left(\mathrm{C}_{10} \mathrm{H}_{16}\right)$ are the same for the four heating times. Moreover, they represent more than $85 \%$ of the mixture for each heating time. We can also 
notice that the amounts emitted for each compound are the largest for a heating time of 30 s indicating that this value can be chosen for the study of the temperature effect on the VOCs' emissions.

We can see in Figure 3 that there are three major compounds, which are the same as those identified for different heating times, and the same for all the heating rates. They represent more than $70 \%$ of the mixture for the five studied heating rates. Let us notice that the evolution of the VOCs relative emission has a non-monotonic behaviour with a maximum emission for $5000 \mathrm{~K} / \mathrm{s}$. This heating rate is the maximum value that can be provided by the flash pyrolysis apparatus (CDS Pyroprobe 5150) and will be selected for the study of the temperature effect on the VOCs' emissions.

Table 1: VOCs emitted by Thymus vulgaris: name, retention time and molecular formula.

\begin{tabular}{|c|c|c|c|}
\hline Compound & $\begin{array}{c}\text { Retention time } \\
{[\mathrm{s}]}\end{array}$ & $\begin{array}{c}\text { Molecular } \\
\text { formula }\end{array}$ & $\begin{array}{c}\text { Molecular } \\
\text { family }\end{array}$ \\
\hline$\alpha$-phellandrene & 8.72 & $\mathrm{C}_{10} \mathrm{H}_{16}$ & Monoterpene \\
\hline$\alpha$-pinene & 8.96 & $\mathrm{C}_{10} \mathrm{H}_{16}$ & Monoterpene \\
\hline 2-thujene & 10.38 & $\mathrm{C}_{10} \mathrm{H}_{16}$ & Monoterpene \\
\hline$\beta$-myrcene & 10.55 & $\mathrm{C}_{10} \mathrm{H}_{16}$ & Monoterpene \\
\hline$p$-mentha-1,4,8-diene & 11.45 & $\mathrm{C}_{10} \mathrm{H}_{16}$ & Monoterpene \\
\hline$p$-cymene & 11.75 & $\mathrm{C}_{10} \mathrm{H}_{14}$ & Monoterpene \\
\hline eucalyptol & 11.96 & $\mathrm{C}_{10} \mathrm{H}_{18} \mathrm{O}$ & $\begin{array}{c}\text { Monoterpenic } \\
\text { ether }\end{array}$ \\
\hline$\gamma$-terpinene & 12.7 & $\mathrm{C}_{10} \mathrm{H}_{16}$ & Monoterpene \\
\hline$\beta$-linalool & 13.95 & $\mathrm{C}_{10} \mathrm{H}_{18} \mathrm{O}$ & $\begin{array}{c}\text { Monoterpenic } \\
\text { alcohol }\end{array}$ \\
\hline $\begin{array}{l}\text { 2-isopropyl-1- } \\
\text { methoxy-4- } \\
\text { methylbenzene }\end{array}$ & 18.03 & $\mathrm{C}_{10} \mathrm{H}_{16} \mathrm{O}$ & $\begin{array}{c}\text { Monoterpenic } \\
\text { ether }\end{array}$ \\
\hline thymol & 19.68 & $\mathrm{C}_{10} \mathrm{H}_{14} \mathrm{O}$ & $\begin{array}{c}\text { Monoterpenic } \\
\text { phenol }\end{array}$ \\
\hline carvacrol & 19.86 & $\mathrm{C}_{10} \mathrm{H}_{14} \mathrm{O}$ & $\begin{array}{c}\text { Monoterpenic } \\
\text { phenol }\end{array}$ \\
\hline caryophyllene & 22.97 & $\mathrm{C}_{15} \mathrm{H}_{24}$ & Sesquiterpene \\
\hline
\end{tabular}

After studying the heating time and heating rate effects on the emission of VOCs, it becomes interesting to investigate the influence of the preheat temperature on these emissions. To proceed, we have selected a heating time of $30 \mathrm{~s}$ and a heating rate of $5000 \mathrm{~K} / \mathrm{s}$ where the VOCs amounts are the largest as stated above.

Figure 4 exhibits the VOCs' emissions of Thymus vulgaris needles for different temperatures: the two major compounds, thymol and $p$-cymene, and the total VOCs are presented. It is clear reading this Figure that the emissions are important for temperature higher than $398 \mathrm{~K}$ and they increase with temperature. 
The total amount emitted at $453 \mathrm{~K}$ is one thousand times higher than the total amount emitted at $343 \mathrm{~K}$, whereas the amount of thymol emitted is 10,000 times higher between 343 and $453 \mathrm{~K}$. The total amount of VOCs emitted is multiplied by 220 between 398 and $453 \mathrm{~K}$ and by 14 between 423 and $453 \mathrm{~K}$. The emissions start to be really important from this last temperature. However, even if it is hard to see it in figure 4 due to the normalization process, a mixture is emitted for low temperatures and is illustrated in the next figure.

Figure 5 presents the composition of VOCs mixture emitted by Thymus vulgaris needles at different temperatures. It is interesting to note that thymol represents more than $50 \%$ of the total emissions for the temperatures where high amount of VOCs are emitted (i.e. after $398 \mathrm{~K}$ ). The highest percentage of thymol in the mixture is reached at $423 \mathrm{~K}$, where it represents more than $72 \%$ of the total VOCs. Thymol is the major component whatever the temperature is, even if it represents only $24 \%$ of the mixture at $363 \mathrm{~K}$. The percentage of the second more important compound, $p$-cymene, is more constant and is between 15 and $25 \%$ for all the temperatures. Except thymol and $p$-cymene, the other compounds represent more than $40 \%$ of the total mixture for temperatures lower than $398 \mathrm{~K}$, but above this temperature they never represent more than $18 \%$ of all of the compounds.

We can notice here the contributions of Parra et al. [12] and Nezhadali et al. [13] for the emissions of Thymus vulgaris under natural conditions. Parra et al. [12] estimated the magnitude of non-methane volatile organic compounds emitted by vegetation in Catalonia, Spain, along with their

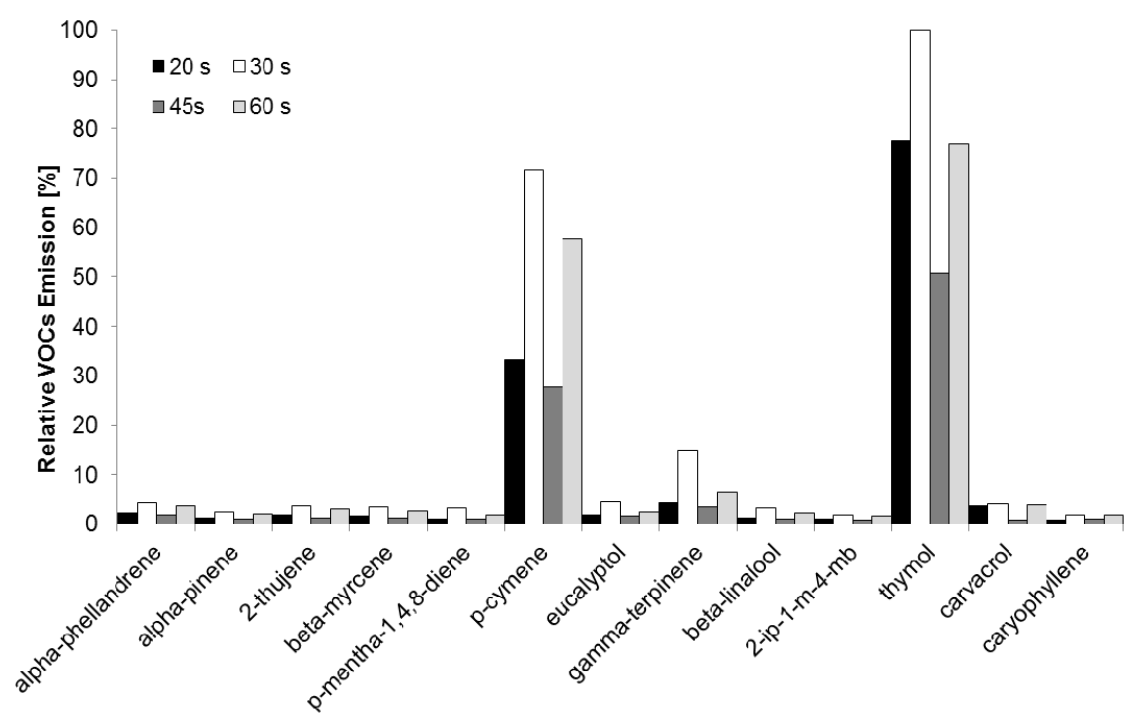

Figure 2: VOCs' emissions of Thymus vulgaris needles at $453 \mathrm{~K}$ for different heating times. 


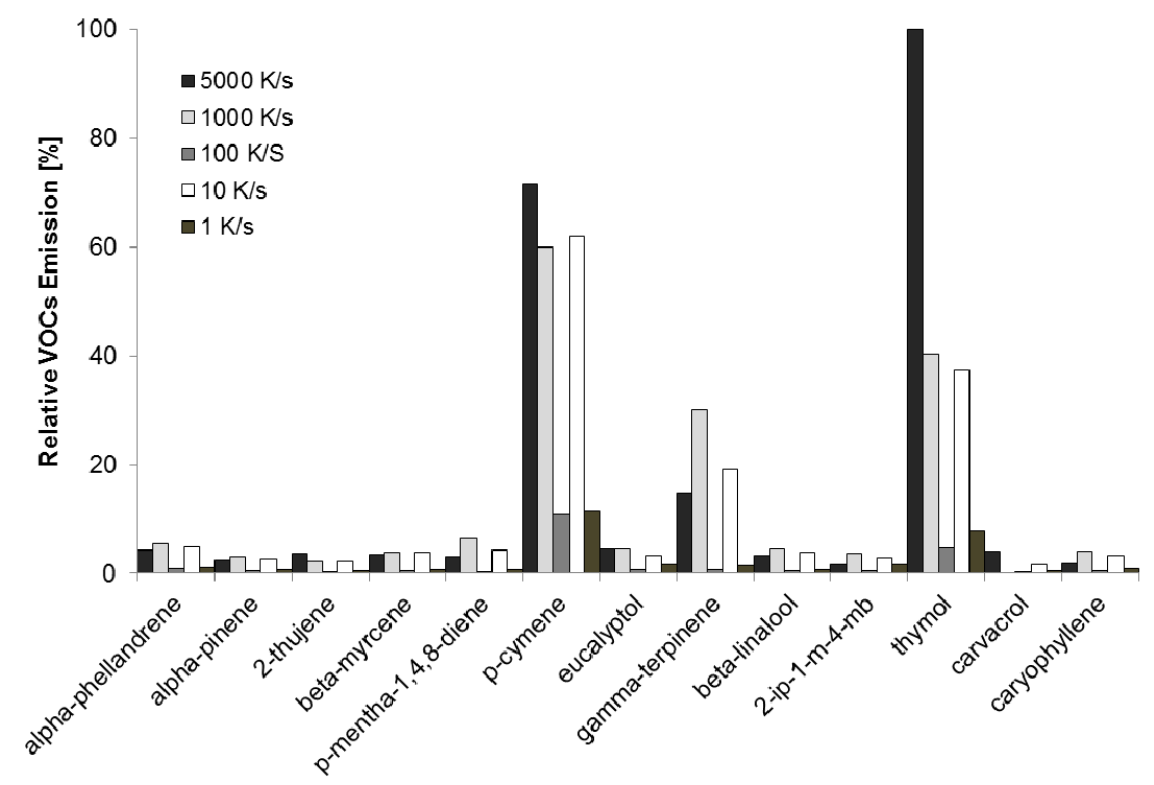

Figure 3: $\quad$ VOCs' emissions of Thymus vulgaris needles at $453 \mathrm{~K}$ for different heating rates.

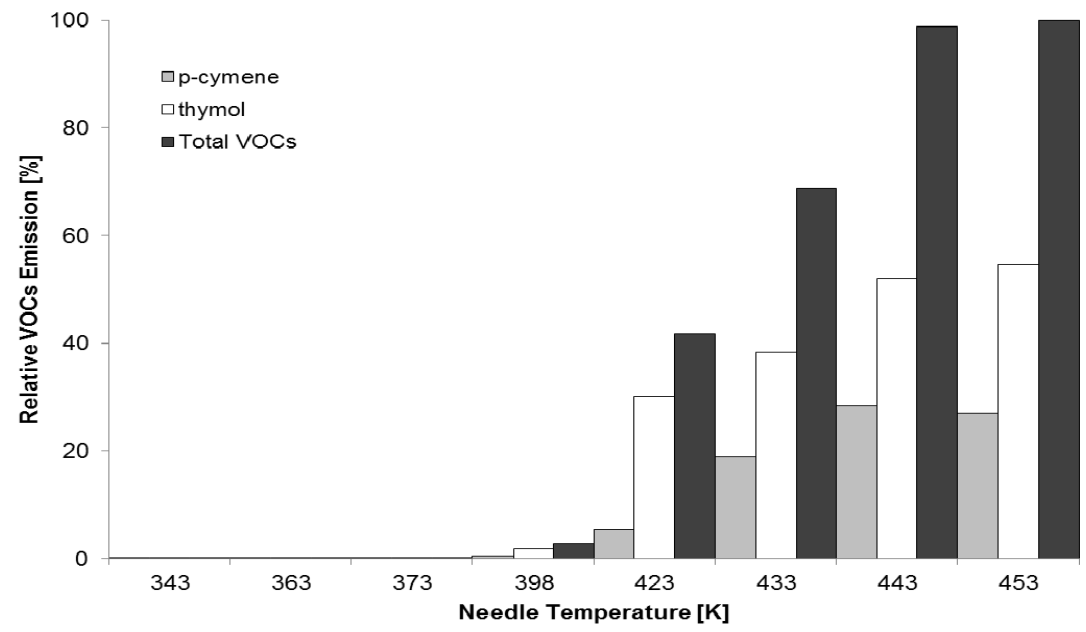

Figure 4: VOCs' emissions of Thymus vulgaris needles for different temperatures.

temporal distribution. They first defined mathematically an emission factor and then found that for Thymus vulgaris it was lower for monoterpenes than for other VOCs. This result is in agreement with our study. In their recent paper, Nezhadali et al. [13] compared the composition of Thymus vulgaris emissions 
using two different extraction methods: hydrodistillation and headspace solid phase microextraction. They found that for both of the methods, the major compounds were thymol, $p$-cymene, $\gamma$-terpinene, myrcene, $\alpha$-pinene and caryophyllene. They found similar results for the two studied methods and concluded that hydrodistillation needs more time and much more amount of plant. They studied the emissions at 298 and $323 \mathrm{~K}$ and we can say that they obtained results very similar to those of our study, even if they only work at low temperatures.

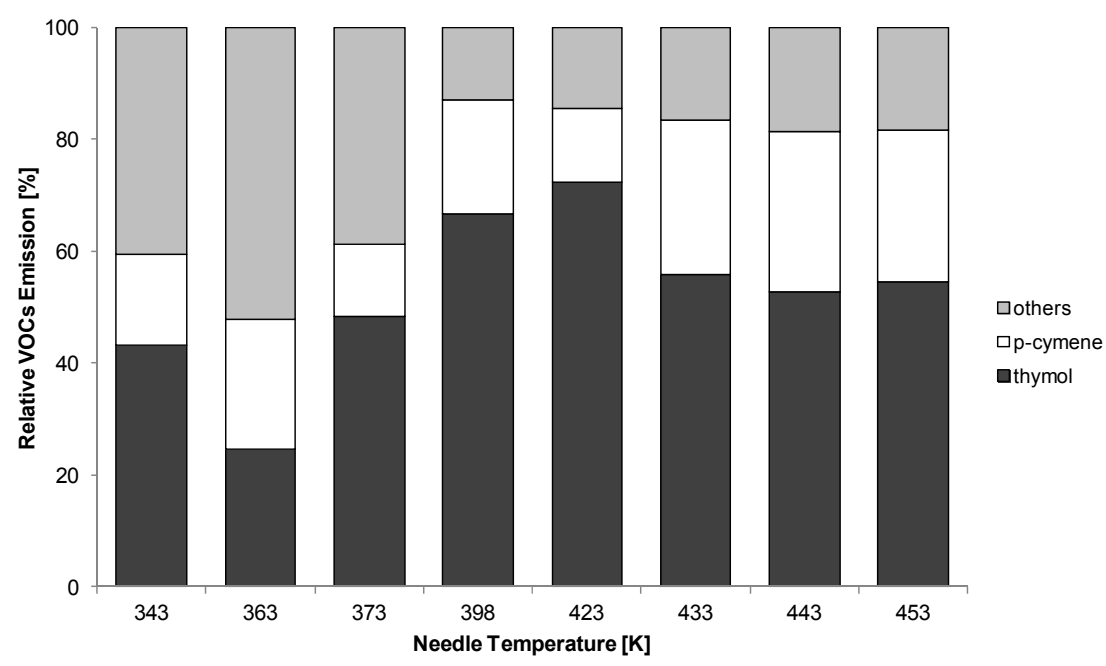

Figure 5: Composition of VOCs mixture emitted by Thymus vulgaris needles at different temperatures.

Another study about the natural emissions of Thymus vulgaris is the one of Owen et al. [2]. These authors studied the VOCs emitted from 40 Mediterranean plant species. They found that the two major compounds for Thymus vulgaris were $p$-cymene and thymol; the following ones were $\alpha$-pinene and $\beta$-myrcene. We can see slight differences between their results and ours, especially for the major compound. These differences can be explained by the differences in the plant characteristics and in the experimental protocol. Indeed, they used plants in the field and ours were grown in a greenhouse and they used a sampling technique called Teflon branch enclosure. This technique is very efficient for natural conditions but is impossible to use while simulating the conditions of an ongoing forest fire.

The emissions behaviour of Thymus vulgaris heated needles is similar to the one of other heated vegetal species that can be found in the literature, with slight differences. The emissions of Rosmarinus officinalis also increase with temperature and we can see two peaks: one around $393 \mathrm{~K}$ and one around $450 \mathrm{~K}$ (Chetehouna [5] and Courty et al. [7]). The first one is due to the water 
evaporation process that increases the transport of VOCs and the second one corresponds to the boiling point of these VOCs. A similar evolution has been observed for Pinus laricio and Pinus pinaster by Barboni et al. [6] with a steep decrease of the emissions after $448 \mathrm{~K}$ [6]. On the contrary, the emissions of Cistus monspeliensis species do not reach a maximum and start to be important at $473 \mathrm{~K}$ [6]. We can say the behaviour of Thymus vulgaris is closer to the evolution of Cistus monspeliensis than to the one of Rosmarinus officinalis, Pinus laricio or Pinus pinaster. This behaviour probably depends on the boiling point value of the major compounds. Indeed, above the boiling point, thermal cracking phenomena can be observed. Oxygenated compounds, which are the major compounds of Cistus monspeliensis and Thymus vulgaris, have boiling point values much higher than monoterpenes. For instance, the boiling points of monoterpenes like $\alpha$-pinene or $\beta$-myrcene are respectively 428 and $440 \mathrm{~K}$, whereas the boiling point of thymol is $506 \mathrm{~K}$ [14].

\section{Conclusion}

The main purpose of this paper was to characterize the VOCs' emissions as functions of temperature of a typical Mediterranean plant usually involved in forest fires, namely Thymus vulgaris. The emissions are studied in a flash pyrolysis device from 343 to $453 \mathrm{~K}$. The influence of two parameters, namely the heating time and heating rate is studied. Maximal emissions were obtained for a heating time of $30 \mathrm{~s}$ and a heating rate of $5000 \mathrm{~K} / \mathrm{s}$. Two major compounds were identified for all the temperatures, thymol $\left(\mathrm{C}_{10} \mathrm{H}_{14} \mathrm{O}\right)$ and $p$-cymene $\left(\mathrm{C}_{10} \mathrm{H}_{14}\right)$. The total amount of VOCs emitted increased with temperature and except for the three lowest temperatures, thymol represented more than $50 \%$ of the gas mixture.

Under certain conditions (wind, moisture content or topography), forest fires behave in a surprising way, starting suddenly to propagate with a rate of spread and an energy released very important Chetehouna [5, 7]. Such fires are named accelerating forest fires and a possible explanation of this phenomenon can be the ignition of a VOCs cloud, emitted by fire heated vegetation and accumulated in flammable conditions. The present study can be useful to better understand this phenomenon as it presents for the first time the VOCs emitted by heated Thymus vulgaris needles.

The strong smell of the VOCs emitted by fire heated vegetation is synonym of high risk for firefighters. They can cause accelerating forest fires and even if they are not in concentration high enough to create a flammable mixture, they contribute to the combustion process during seasons where the plants are highly flammable. The present study could be the first step of the creation of VOCs remote sensors that could become equipment to protect firefighters. To do so, other studies must be conducted on the emissions of VOCs by heated vegetal species. 


\section{References}

[1] Catoire, L., Naudet, V., Estimation of temperature-dependent lower flammability limit of pure organic compounds in air at atmospheric pressure. Process safety progress, 24, pp.130-137, 2005.

[2] Owen, S.M., Boissard, C., Hewitt, C.N., Volatile organic compounds (VOCs) emitted from 40 Mediterranean plant species: VOC speciation and extrapolation to habitat scale. Atmospheric Environment, 35, pp.53935409, 2001.

[3] Ormeño, E., Fernandez, C., Mévy J.P., Plant coexistence alters terpene emission and content of Mediterranean species. Phytochemistry, 68(6), pp. 840-852, 2007.

[4] Macchioni, F., Cioni, P. L., Flamini, G., Morelli, I., Maccioni, S., Ansaldi, M., Chemical composition of essential oils from needles, branches and cones of Pinus pinea, P. halepensis, P. pinaster and P. nigra from central Italy. Flavour and Fragrance Journal, 18, pp.139-143, 2003.

[5] Chetehouna, K., Barboni, T., Zarguili, I., Leoni, E., Simeoni, A., Fernandez-Pello A.C., Investigation on the emission of Volatile Organic Compounds from heated vegetation and their potential to cause an accelerating forest fire. Combustion Science and Technology, 181, pp. 1273-1288, 2009.

[6] Barboni, T., Cannac, M., Leoni, E., Chiaramonti, N., Emission of biogenic volatile organic compounds involved in eruptive fire: implications for the safety of firefighters. International Journal of Wildland Fire, 20(1), pp.152-161, 2011.

[7] Courty, L., Chetehouna, K., Halter, F., Foucher, F., Garo, J.P., MounaïmRousselle, C., Experimental determination of emission and laminar burning speeds of $\alpha$-pinene. Combustion and Flame, In Press, 2011.

[8] Kaloustian, J., El-Moselhy, T.F., Portugal, H., Chemical and thermal analysis of the biopolymers in thyme (Thymus vulgaris). Thermochimica Acta, 401, pp.77-86, 2003.

[9] Bradley, A.S., Organic geochemical biosignatures in alkaline hydrothermal ecosystems, PhD Thesis, Massachusetts Institute of Technology, 269 p., 2008.

[10] Lou, R., Wu, S.B., Lv, G.J., Effect of conditions on fast pyrolysis of bamboo lignin. Journal of Analytical and Applied Pyrolysis, 89, pp.191196, 2010.

[11] Ngo, P.T., Rumpel, C., Dignac, M.F., Billou, D., Duc, T.T., Jouquet, P., Transformation of buffalo manure by composting or vermicomposting to rehabilitate degraded tropical soils. Ecological Engineering, 37, pp.269276, 2011.

[12] Parra, R., Gasso, S., Baldasano, J.M., Estimating the biogenic emissions of non-methane volatile organic compounds from the North Western Mediterranean vegetation of Catalonia, Spain. Science of the Total Environment, 329, pp.241-259, 2004. 
198 Modelling, Monitoring and Management of Forest Fires III

[13] Nezhadali, A., Akbarpour, M., Shirvan B.Z., Mousavi, M., Comparison of volatile organic compounds of Thymus vulgaris using hydrodistillation and headspace solid phase microextraction gas chromatography mass spectrometry. Journal of the Chinese Chemical Society, 57, pp.40-43, 2010.

[14] Babrauskas, V., Ignition Handbook, Fire Science Publishers/Society of Fire Protection Engineers, Issaquah, USA, 2003. 